\title{
INFLUÊNCIAS DA TECNOLOGIA PARA A INOVAÇÃO EM SERVIÇOS
}

\author{
Technology influence on service innovation
}

\author{
Claudia Fernanda Franceschi Klement ${ }^{1}$ \\ Abraham Sin Oih $\mathrm{Yu}^{2}$
}

\section{Resumo}

O presente ensaio teórico resgata o conceito de serviço, tendo como enfoque a inovação no setor de serviços. Após a exposição sobre a importância do setor na economia nacional e mundial e descrição sobre as características peculiares que diferenciam os serviços dos bens, faz-se uma explanação sobre como a teoria tem tratado a questão de inovação em serviços. Finalmente, destaca-se o importante papel da tecnologia como meio para inovação em serviços, principalmente no que tange os serviços voltados para a informação.

Palavras-chave: Tecnologia; Inovação; Serviços.

\section{Abstract}

This theoretical study presents the service concept focusing on service innovation. First of all is presented the importance of this sector in Brazilian and international economies, then it describes the characteristics that distinguish services from goods and it explains how the innovation theme is treated in the service sector. Finally, the important technology role for the service innovation is raised, especially for services that are based on information.

Keywords: Technology; Innovation; Services.

\footnotetext{
${ }^{1}$ Doutora em Administração, Professora Assistente Associada da Universidade Presbiteriana Mackenzie, Reitoria, Faculdade de Ciências Econômicas, Contábeis e Administrativa, Rua da Consolação, 930, Ed. João Calvino, sala 205, Consolação, 01302-907 - São Paulo, SP, Brasil. E-mail: klement@mackenzie.br

${ }^{2}$ Livre-Docente em Administração pela Universidade de São Paulo. Atualmente é Professor Associado da Universidade de São Paulo e pesquisador do Instituto de Pesquisas Tecnológicas do Estado de São Paulo, Divisão de Economia e Engenharia de Sistemas, Av. Prof. Almeida Prado, 532, Cidade Universitária Armando de Salles Oliveira, Butantã, 05508-900, São Paulo, SP, Brasil, caixa postal 0141.E-mail: abraoyu@ipt.br
} 


\section{Introdução}

O setor de serviços tem ganhado uma importância bastante grande nos últimos anos, quer seja pela contribuição no produto interno bruto, quer seja pela participação no emprego total. Assim como se percebe uma expansão na indústria de serviços no concernente à participação no Produto Interno Bruto no Brasil, também a participação do setor de serviços no emprego total tem crescido paulatinamente, enquanto no setor primário tem decrescido e no setor secundário tem se mantido quase inerte.

No Brasil, de 1998 a 2001, as micro e pequenas empresas de serviços tiveram um crescimento médio real de $2,9 \%$ ao ano em termos reais, acompanhando o crescimento das médias e grandes empresas, que foi de 3,0\% ao ano nesse mesmo período. Em 2002, a Pesquisa Anual de Serviços detectou cerca de 945 mil empresas de serviços mercantis nãofinanceiros ocupando 6.856 mil pessoas e pagando $R \$ 55,1$ bilhões em salários, retiradas e outras remunerações. Foi de $\mathrm{R} \$ 290,5$ bilhões a receita operacional líquida das atividades pesquisadas. A mesma pesquisa destaca ainda que o maior número de empresas de serviços encontra-se nas atividades de serviços prestados às empresas e serviços de alojamento e alimentação, seguidos por transportes e serviços auxiliares (IBGE, 2002).

Uma vez que se pôde constatar a importância do setor de serviços na economia brasileira, pode-se perceber que este é um tema de grande relevância. Além da demanda final, há uma crescente demanda intermediária das organizações por serviços em razão do papel da informação e do conhecimento na sociedade, uma vez que as empresas, por razões econômicas, têm preferido abastecer-se a fazer. O setor industrial tem descoberto e incorporado a noção de serviço, assim como o setor de serviços tem industrializado sua forma de funcionamento (ZARIFIAN, 2001a). Dessa forma, as organizações de serviços, assim como as organizações industriais, são compostas por três grandes atividades: o da concepção das novas tecnologias e dos novos produtos e serviços, o dos grandes sistemas técnicos que asseguram a produção material desses produtos ou serviços e o da relação direta com os clientes ou usuários.

Tendo em conta que para a eficiência do serviço é importante a integração das três dimensões anteriormente citadas, primeiramente há que se interpretar e compreender as expectativas do cliente-usuário, para depois se desenvolver um conjunto de técnicas de levantamento de informações e finalmente estabelecer uma distinção entre regime de inovação (quando os clientes ainda são potenciais) e regime de rotina (modos e formas de serviços já existentes). Quando interpretação e compreensão exigem a elaboração de soluções diferenciadas para os clientes-usuários, diz-se que as soluções devem ser criadas para atender a uma necessidade não satisfeita dos clientes-usuários e é aí que entra o papel da inovação.

Assim sendo, o presente ensaio teórico apresenta a conceituação sobre serviço, descrevendo as características peculiares que diferenciam os serviços dos bens e fazendo uma explanação sobre como a teoria tem tratado a questão de inovação em serviços. Ao final, destacase o importante papel da tecnologia como meio para inovação em serviços, principalmente no que tange os serviços voltados para a informação

\section{Serviços}

Serviço é uma organização e uma mobilização, o mais eficiente possível, de recursos para interpretar, compreender e gerar a mudança perseguida nas condições de atividade do cliente-usuário (ZARIFIAN, 2001b). Conforme Fitzsimmons e Fitzsimmons (2000), mesmo quando difícil de ser feita, existe distinção entre bem e serviço. Os autores utilizam uma 
classificação de serviços baseada na grande interação do cliente e na intensidade do grau de trabalho. Assim sendo, destacam as seguintes características especiais que diferenciam os serviços dos bens:

- consumidor participa no processo da prestação do serviço: ao invés de ser um consumidor passivo, ele se transforma num agregador do produto (serviço);

- produção e consumo simultâneos do serviço: uma vez que o consumidor é ativo na prestação do serviço, existe simultaneidade entre o momento da produção e do consumo;

- perecibilidade da capacidade: os serviços operam em um sistema aberto, com o impacto total das variações da demanda sendo transmitidos para o sistema;

- seleção da localização em função dos consumidores: o prestador do serviço e o consumidor devem se encontrar, portanto, a localização deve considerar a possibilidade de acesso do consumidor;

- intensidade do trabalho: quando a atividade é centrada nas pessoas, exige mais experiência do prestador de serviço; a automação pode eliminar as relações pessoais, mas provoca o aumento da atenção ao trabalho, o que pode gerar uma variação no serviço;

- intangibilidade: os serviços são atividades, enquanto bens são objetos, assim eles constituem um problema para os consumidores que dificilmente poderão testar sua eficiência; apenas deverão se basear na reputação dos prestadores desses serviços;

- dificuldade para medição da produção: como para cada cliente o serviço prestado é diferente, por maior que seja a padronização, a avaliação de um serviço deve ser feita através do acompanhamento do processo ou através de pesquisa de mercado.

Shostack (1987) explica que serviços não são "coisas", portanto devem ser percebidos como processos em vez de objetos. Como processos, os serviços têm as características já citadas (intangibilidade, perecibilidade, simultaneidade na produção/consumo e participação do consumidor na prestação do serviço). A autora sugere dois caminhos para a descrição do processo de serviço: um de acordo com as etapas e seqüências que constituem o processo (complexidade do processo) e outro em consonância com a variabilidade dessas etapas e seqüências (diversidade).

Kang e McDermott (2000) reiteram as colocações de que os serviços diferenciam-se da manufatura nas quatro questões genéricas: intangibilidade, heterogeneidade, perecibilidade da saída e simultaneidade de produção e consumo. Apontando esta classificação inicial como genérica demais, argumentando que há a necessidade de se incluir as pessoas como parte do sistema de serviços, assim como o fazem Shostack (1987) e Fitzsimmons e Fitzsimmons (2000). Dessta forma, em linhas gerais, os serviços vistos como processos são analisados, basicamente, em relação às seguintes dimensões: complexidade/diversidade, tangibilidade/intangibilidade, baseados em pessoas/baseados em tecnologia, grande/baixa demanda, tempo de contato com o prestador de serviço.

A Figura 1 apresenta um modelo para análise da prestação de serviços realizada pela linha de frente (front office) nas organizações. O modelo para análise do trabalho da linha de frente parte da tríade de Kingman-Brundage (1995), composta pelas lógicas do cliente, técnica e do empregado. O valor do serviço pode ser percebido pela lógica do cliente a partir de dois pontos, conforme Zarifian (2001b). No encontro entre cliente e empregado, o valor do serviço pode ser percebido pela competência profissional dos empregados em identificar e conhecer a atividade do cliente-usuário e em interpretar e compreender o problema do destinatário do serviço. Na interface técnica, a organização oferece o valor para o cliente (e sociedade), de acordo com Zarifian (2001b), a partir das conseqüências, ou seja, oferecendo um serviço que atenda aos aspectos de avaliação da utilidade, da justiça, da solidariedade e da estética. 
Ainda para Zarifian (2001b), em uma abordagem do valor do serviço, a gestão do serviço deve compreender a pertinência (atividade a partir do contato do empregado de linha de frente com o cliente) no intuito de coadunar objetivos organizacionais e expectativas do cliente. Deve, ainda, compreender a eficiência e eficácia, preocupações da lógica técnica, que coordena, respectivamente, as expectativas dos clientes com os recursos organizacionais disponíveis e estes com os objetivos da entidade prestadora de serviço (interface de suporte). Através da relação entre resultados alcançados com objetivos e recursos organizacionais, a entidade pode controlar como estão sua eficiência e pertinência.

Estes resultados representam, não somente o controle, mas um elemento fundamental no conceito do serviço, conforme Heskett e Schlesinger (1997). Através dele pode-se equacionar o valor do serviço aumentando a qualidade deste e diminuindo seus custos. Conforme Heskett e Schlesinger (1997), a estratégia da cadeia serviço-lucro deve contemplar resultados de qualidade e produtividade (através da capacitação e satisfação dos funcionários e de estratégias operacionais) para aumentar o valor do serviço, chegando, assim, à satisfação e fidelização do cliente e, conseqüentemente, ao crescimento da receita e lucratividade da organização.

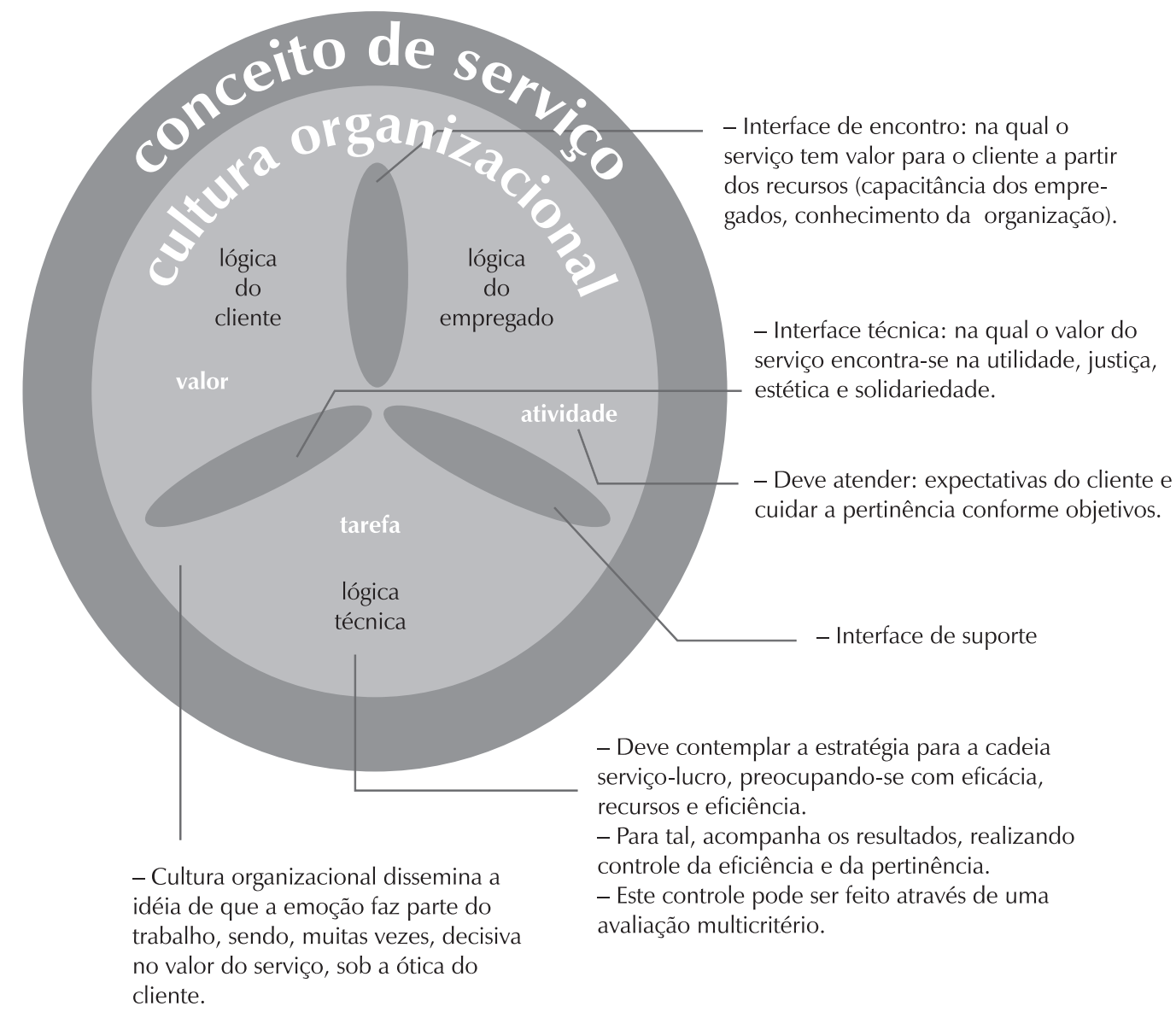

Fonte: Adaptado de Kingman-Brundage (1995); Zarifian (2001b) e Gadrey (2001).

Figura 1 - Modelo para análise do trabalho da linha de frente

A visão de serviço estratégico de Heskett (1997) consiste em quatro elementos:

- identificação do segmento de mercado-alvo;

- desenvolvimento de um conceito de serviço para contemplar as necessidades de consumidores-alvo; 
- priorização dos processos operacionais para sustentar o conceito de serviço;

- projeção de um sistema de entrega de serviço para suportar a estratégia operacional.

Esta visão estratégica pode acoplar uma avaliação multicritério para acompanhar os controles de pertinência e eficiência organizacionais. Conforme Gadrey (2001), critérios técnicos, financeiros, de relacionamento, ecológicos, de inovação e reputação podem fornecer à organização prestadora de serviço o feedback necessário sobre sua produtividade.

Silvestro (1999) propõe uma matriz de classificação dos serviços pautada pelo volume produtivo da organização - que no modelo do processo de serviço é definido como o volume de clientes processados por unidade de negócio por período -, e pela variedade, que representa um grupo de características do serviço - foco nas pessoas/equipamentos, nível de contato com o cliente, valor agregado no front office, grau de customização, grau de discrição do empregado e foco no produto/processo (ver Figura 2).

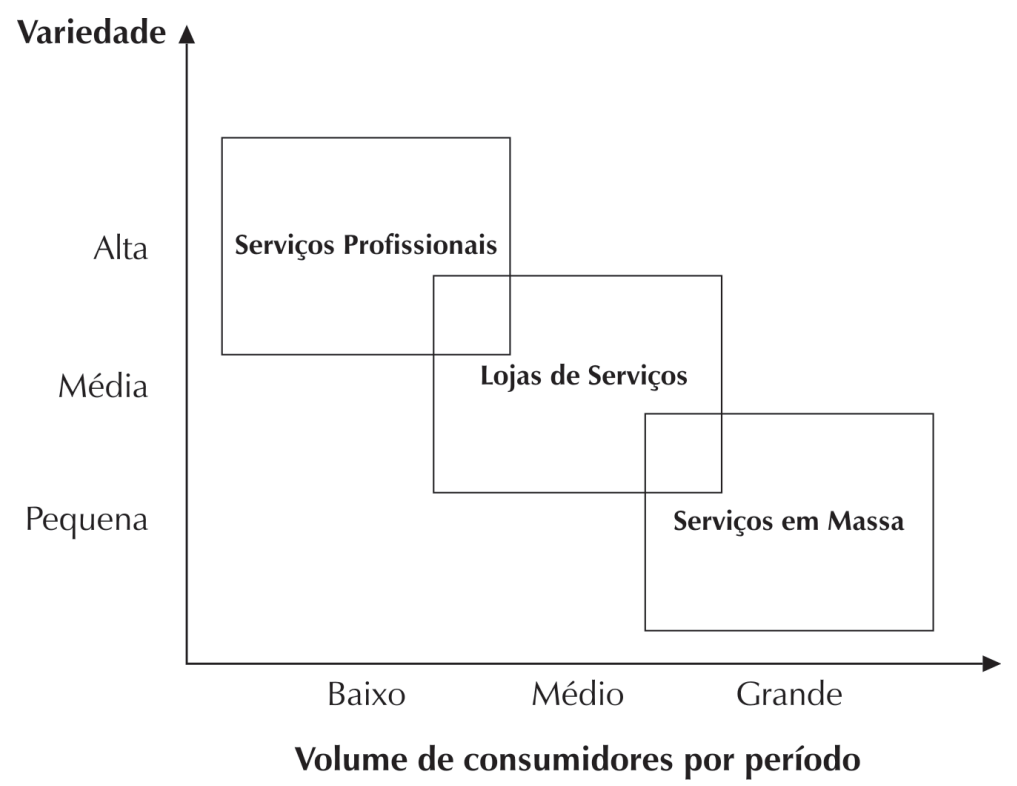

Fonte: Silvestro (1999, p. 401).

Figura 2 - Matriz de classificação dos serviços

Uma vez que o modelo da Figura 2 já é apresentado e discutido no meio acadêmico desde 1992, Collier e Meyer (1998) criticam este modelo baseado na matriz produto-processo em um de seus trabalhos, pois argumentam que esta relação entre produto e processo não é encontrada em muitos serviços. Dentre os exemplos citados pelos autores, está o aumento no volume de negócios de empresas hoteleiras que, historicamente, aumentam o número de unidades, mas não modificam seus processos.

Outra crítica dos autores refere-se à complexidade das seis dimensões que compõem o eixo vertical. Para esses autores, não é clara a forma como essas seis dimensões estão definidas em um único eixo. Mas os autores fazem uma ressalva a esta crítica, pois reconhecem que, com o aumento da capacidade de informação tecnológica, volume de serviço pode estar mais relacionado com decisões sobre o design do processo, especialmente em negócios com alto volume de informações.

A partir da análise dessa matriz e do estudo de outros autores, Collier e Meyer (1998) propõem uma nova matriz de posicionamento de serviço. Esta matriz está baseada em dois eixos: 
o eixo vertical retrata o número de caminhos construídos no sistema de serviço pela gerência; o eixo horizontal retrata a seqüência de atividades do encontro de serviço do cliente.

Dessa forma, os autores apresentam uma classificação das empresas de serviço baseada em três aspectos: a direção do processo deriva da natureza do desejo do cliente; os resultados da performance do serviço encontram-se na diagonal da matriz; os dois eixos são conceitualmente independentes. Assim, os autores classificam os serviços em três tipos: os roteados pelo cliente, os co-roteados (cliente e organização direcionam o serviço) e os roteados pelo prestador de serviço.

Percebendo o crescimento do setor de serviços na economia mundial e compreendendo as características do setor, autores estudam a questão da inovação nos serviços, no intuito de entender o papel da inovação neste setor, verificando como ela acontece, sobre que bases ela se desenvolve e quais são os impactos no setor.

\section{Inovação em serviços}

Inovação pode ser definida, conforme Pavitt (1984), como um produto ou processo produtivo novo ou melhor, usado ou comercializado com sucesso por uma organização. Ainda de acordo com o mesmo autor, é reconhecido o fato de que a produção, adoção e difusão da inovação, principalmente tecnológica, são essenciais para o desenvolvimento econômico e para as mudanças sociais nos países. Esta idéia pode ser reforçada pela argumentação de Utterback (1994) de que inovação é um determinante central de sucesso ou fracasso nas empresas manufatureiras.

A colocação anterior pode ser estendida a outros setores produtivos. Nos dias atuais, a tecnologia, não somente em termos instrumentais, mas também em termos de técnicas e conhecimento, é condição sine qua non para organizações que desejam perpetuar-se em um mercado cada vez mais competitivo e instável. As mudanças são cada vez maiores e mais rápidas, forçando as empresas a desenvolverem flexibilidade e a enxugarem sua estrutura, para poderem adaptar-se de forma mais ágil ao ambiente e, concomitantemente, evitarem desperdícios (WOMACK e JONES, 1998).

O mercado consumidor passou a exigir um tratamento individualizado, fazendo com que as empresas, entre outras medidas, diminuíssem o ciclo de desenvolvimento de novos produtos. Para conseguir isso, empresas têm adotado as mais variadas estratégias para o processo de inovação, buscando escolher o projeto certo e manter-se em vantagem competitiva, uma vez que esta é temporária (FINE, 1999).

A inovação deve visar aumento da qualidade, diminuição de custos do ciclo de vida do produto e redução do tempo de desenvolvimento, e uma das suas características é o foco nas necessidades do consumidor. Dessa forma, através da inovação, as empresas buscam atender às exigências de eficiência e tempo de resposta dos consumidores, assim como aumentar sua produtividade, melhorar a qualidade do produto e, principalmente, diminuir o ciclo de projetos, no intuito de manterem-se à frente da concorrência.

Geralmente as teorias sobre mudanças tecnológicas, que podem ser expandidas para as inovações em geral, estão classificadas em duas amplas categorias, conforme Dosi (1982):

- mudanças que ocorrem a partir da tecnologia "empurrada": modificações a partir da organização e da produção. Novos produtos e processos gerados a partir do desenvolvimento de novo conhecimento ou de novas formas de utilização do conhecimento existente, conforme classificação de Henderson e Clark (1990); do consumidor.

- mudanças geradas a partir das necessidades de mercado ou, mais especificamente, 
Gopalakrishnan e Damapour (1997) explicam que as inovações devem ser compreendidas a partir de três dimensões primárias, que são: o estágio do processo de inovação, os níveis de análise e o tipo de inovação. Os autores entendem como estágios do processo de inovação a geração e a adoção da inovação, distinguindo assim dois tipos de organizações: aquelas que são geradoras e aquelas que adotam as inovações. Os níveis de análise também podem ser diferenciados, dependendo da inovação: indústria, organização, subunidade (área, departamento) ou, ainda, a inovação por si só. E finalmente os tipos de inovação que podem ser: produto ou processo, radical ou incremental e técnica ou administrativa.

Sobre inovação em serviços, mais especificamente, Gallouj (1998) explica que existem três abordagens teóricas principais: abordagem baseada em serviços, abordagem integradora e abordagem tecnicista. A abordagem baseada em, ou orientada para, serviços enfatiza as especificidades de inovação em serviços e mostra inovações particulares, em especial uma grande freqüência de inovações ad hoc. As inovações ad hoc são construções interativas entre organização e cliente de uma solução para um problema particular, portanto, dificilmente passível de replicação (SUNDBO e GALLOUJ, 1998). Gallouj (1998) explica ainda que esta abordagem é especialmente definida por uma distinção entre serviços essenciais e serviços periféricos. Por serviços essenciais entende-se a parte intangível do serviço, que representa o motivo de sua existência; por serviço periférico, entende-se serviço agregado ao essencial de pouca importância ou sem importância independente, podendo apresentar uma evidência tangível (SHOSTACK, 1982).

Ainda de acordo com Gallouj (1998), abordagem integradora é aquela que concilia inovação de bens e serviços sob uma única teoria de inovação. São abordagens baseadas em concepções funcionais do produto e propõem tipologias de formas de inovação válidas tanto para serviços, quanto para bens.

Finalmente Gallouj (1998) explica que a abordagem baseada em tecnologia, ou tecnicista, pode ser resumida como a introdução de equipamentos ou sistemas técnicos na organização. O autor considera o modelo de ciclo reverso do produto, de Barras, ideal no que tange esta abordagem, pois apresenta um estudo na geração de inovação nos serviços por eles mesmos e não somente como resultado de inovações tecnológicas desenvolvidas no setor de produção de bens. O autor explica, ainda, que, no modelo de Barras, a evolução nos serviços se dá de forma reversa, porque a fase incremental do processo de inovação será seguida pela fase radical, assim, a proposta é de que são as melhorias em eficiência e qualidade do serviço que geram um novo serviço. O modelo percebe a inovação em serviços de forma dinâmica, através de três estágios.

Barras (1986) desenvolveu seu modelo a partir de uma questão central: Como acontece a inovação em indústrias de bens e serviços? A resposta foi um modelo de inovação que espelhasse a teoria do ciclo do produto, uma vez que esta era aplicada para a produção de bens que abarcava novas tecnologias. Este modelo, derivado de um estudo empírico, assume que a adoção de informação tecnológica em indústrias de serviços tem sido expressa pelo "ciclo reverso do produto". Em linhas gerais, o autor explica que as três fases do ciclo reverso do produto consistem no seguinte: em uma primeira etapa, as aplicações de novas tecnologias são desenhadas para melhorar a eficiência e entrega de serviços existentes; na segunda etapa, a tecnologia é aplicada para melhorar a qualidade dos serviços e, somente na terceira etapa, a tecnologia é geradora de uma total transformação para novos serviços.

Conforme Sundbo e Gallouj (1998), inovação é a mudança de um negócio através da adição de um novo elemento ou a nova combinação de antigos elementos, devendo ser um fenômeno que possa ser reproduzido. Entendem também como inovação em serviço não somente uma inovação tecnológica, mas a criação de um novo conhecimento ou informação. 
Em geral, inovações em serviços são constituídas por ajustes em processos e têm características muito mais incrementais do que radicais, assim, seu tempo de desenvolvimento é relativamente menor, desde que não haja necessidade de pesquisa ou busca de conhecimento científico.

De acordo com Sundbo e Gallouj (1998), pode-se classificar a inovação em serviços em cinco tipos: inovação em produto, inovação em processo (renovação de procedimentos produtivos e distribuição/entrega), inovação organizacional (novas formas de organização e gestão), inovação no mercado (novo comportamento do mercado) e, como explicado anteriormente, ainda as inovações ad hoc (aquelas que atendem necessidades particulares dos clientes).

Uma vez que há simultaneidade entre produção e consumo do serviço, é praticamente impossível, segundo os autores, realizar uma mudança no produto sem realizar mudanças no processo. Dessa forma, inovação em serviços geralmente implica em mudanças em elementos do processo produtivo e do produto, simultaneamente (SUNDBO e GALLOUJ, 1998).

Diante da importância da interação entre cliente e organização no momento da prestação de serviços, Abramovici e Bancel-Charensol (2004) fizeram um estudo considerando a integração do cliente no projeto de inovação em serviços. O objetivo do estudo era integrar a validação da inovação pelo cliente desde a concepção até a implementação. Foram estudadas empresas que ofereciam serviço de massa, conforme classificação de Silvestro (1999), e exigiam maior participação dos clientes.

Dentre os resultados do estudo, dois chamam a atenção. Primeiro o fato de os pesquisadores utilizarem um modelo dividido em quatro estágios, que lembra bastante algumas etapas do modelo de processo decisório de Mintzberg, Raisinghani e Theorê (1976): fase da identificação das necessidades; fase da interpretação das necessidades; fase de desenvolvimento; fase de validação. O segundo é que a diversidade de modelos deve considerar um balanceamento entre risco/fidelidade/custo que seja consistente com o projeto da organização.

As forças que dirigem o processo de inovação podem ser externas ou internas. As forças externas, segundo Sundbo e Gallouj (1998), estão relacionadas como as trajetórias institucionais, tecnológicas, gerenciais, sociais e profissionais que influenciam determinados serviços, além das relações específicas estabelecidas com os competidores, fornecedores, com o setor público e, especialmente, com os clientes. As forças internas, por sua vez, são estabelecidas pela existência, ou não, de estruturas formais dedicadas à inovação, pelo envolvimento dos trabalhadores no processo de mudança e pela integração do processo de inovação ao planejamento estratégico da organização. As diferentes formas como estas forças podem se combinar em cada situação específica determinará o padrão de inovação.

Utterback (1994) explica que a idéia de design dominante e inter-relações entre inovação em produto e processo, apresentados no modelo para produtos montados, é substituída pela idéia de tecnologia habilitadora para produtos não-montados, como petroquímicos, fios de cobre, fibras sintéticas e milhares de outros produtos homogêneos. $O$ autor apresenta o exemplo da lâmina de vidro para mostrar os processos de inovação que têm sido feitos de forma barata em todo lugar. A moderna indústria de vidro é dividida em dois grandes segmentos: vidro plano e vidro moldado. Essa evolução exigiu a combinação e eliminação de etapas na produção do vidro. Cada combinação representou uma mudança na arquitetura do processo. Cada nova arquitetura resultou em baixa de custos, o relacionamento entre tempo, unidade, custo e arquitetura do processo diminuiu a estrutura. O exemplo demonstra que as tecnologias surgiram em um momento e foram refinadas incrementalmente ao longo dos anos.

Esta colocação de Utterback (1994), sobre a evolução dos bens não-montados através de inovações incrementais em virtude da ênfase no processo, está muito próxima ao que alguns autores que estudam inovação em serviços (BARRAS, 1986; GALLOUJ, 1997; SUNDBO e 
GALLOUJ, 1998; GALLOUJ e WEINSTEIN, 1997) explicam sobre como o processo de inovação se dá nos serviços em geral. Uma das características marcantes nos serviços em geral, é a idéia de que as inovações acontecem incrementalmente e, após várias modificações incrementais no processo, acontece uma mudança efetiva no produto, pela característica de o produto nos serviços ser um processo ou um conjunto de processos.

Gallouj e Weinstein (1997) explicam que se, de um lado, a teoria da inovação tem se desenvolvido com base na análise da inovação tecnológica em atividades manufatureiras; por outro lado, as particularidades das atividades de serviços dificultam a sua mensuração através dos métodos tradicionais da economia (produtividade) e a verificação de melhorias ou mudanças (em nível qualitativo). Por esses motivos, os autores se concentraram em dois grupos distintos de estudos: um focado na análise da introdução de equipamentos e sistemas técnicos em empresas prestadoras de serviços e indústrias e o outro focado num conjunto de estudos nos quais se crê que a inovação pode existir sem a influência tecnológica.

Os autores apresentam, então, a idéia de que a inovação deve ser vista sob uma ótica integradora. Em primeiro lugar, esta visão envolve inovação tanto em bens quanto em serviços. Em segundo lugar, esta visão utiliza ambos, inovação tecnológica por si só e formas não-tecnológicas de inovação (GALLOUJ e WEINSTEIN, 1997).

Sundbo e Gallouj (1998) explicam que a inovação em serviços pode ser orientada pela necessidade do cliente (inovação "puxada") ou pela percepção da organização de uma lacuna (inovação "empurrada"). Os autores explicam também que é difícil estabelecer indicadores de inovação em serviços, a maioria dos indicadores está ligada à Pesquisa e Desenvolvimento em organizações produtoras de bens, e em serviços raramente esta atividade é formalizada. Assim, os autores sugerem indicadores como aquisição de patentes, treinamento ou, como Fitzsimmons e Fitzsimmons (2000), pesquisa de mercado. Pode-se, ainda, utilizar mensurações, tais como: formação dos empregados, informações sobre custos de desenvolvimento e marketing.

Após discutirem as características específicas dos serviços e apresentarem uma representação genérica de produto (bens e serviços) em seu trabalho, Gallouj e Weinstein (1997) propõem modelos de inovação a partir de sua visão integradora. Nessa proposta os autores rompem a dicotomia inovações radicais/não-radicais e apresentam outras formas de melhoria dos produtos. Assim, os autores apresentam a seguinte classificação:

- inovação radical: criação de um produto completamente novo;

- inovação por melhoria: melhoria de algumas características sem modificação na estrutura do sistema;

- inovação incremental: a estrutura geral do sistema permanece a mesma, mas o sistema é modificado marginalmente através da adição de novos elementos ou da substituição de elementos;

- inovação ad hoc: construção interativa de uma solução para um problema particular de um cliente;

- inovação recombinativa: também chamada inovação arquitetural, é a inovação através de uma nova combinação das características finais ou técnicas, derivada de um "estoque" do conhecimento da organização;

- inovação por formalização: consiste em organizar as características do serviço, especificando-as, tornando-as menos vagas e dando-lhes forma.

Pode-se perceber que esta classificação está fortemente ligada aos modelos criados a partir de estudos nas indústrias manufatureiras, estudos como de Abernathy e Clark (1985), Henderson e Clark (1990) e Wheelwright e Clark (1990). A classificação tradicional da economia divide a inovação, em geral, em dois grandes grupos: inovações incrementais e inovações radicais. Henderson e Clark (1990) explicam que a inovação incremental introduz mudanças 
relativamente menores ao produto existente, aproveita o potencial do design dominante e, muitas vezes, o reforça. Já a inovação radical é baseada em um novo conjunto de princípios científicos e de engenharia e, freqüentemente, abre novos mercados e aplicações potenciais, podendo servir como entrada para novas empresas ou até mesmo para redefinir uma indústria.

Henderson e Clark (1990) explicam ainda que esta classificação produziu importantes resultados, mas é incompleta, pois é crescente o número de evidências de inovações técnicas que envolvem mudanças modestas na tecnologia existente tendo conseqüências competitivas dramáticas.

Para Abernathy e Clark (1985), existem critérios para a categorização da inovação em termos de sua significância competitiva, baseados na noção de que a vantagem competitiva depende da aquisição ou desenvolvimento de habilidades particulares, relacionamentos e recursos. Os autores apresentam quatro diferentes formas de inovação:

- arquitetural, na qual a inovação repousa sobre novas ligações com o mercado;

- nicho de mercado, abertura de novas oportunidades de mercado;

- regular, evolução de competências e mercados já conquistados;

- revolucionária, ruptura com competências e mercados estabelecidos.

Essas formas são baseadas em duas dimensões. A primeira dimensão é referente à manutenção versus ruptura do mercado existente e a segunda diz respeito à manutenção versus ruptura das competências desenvolvidas na organização.

Henderson e Clark (1990) corroboram esta colocação. Para esses autores, as inovações podem ser de diferentes tipos, com diferentes efeitos competitivos. Assim, os autores consideram que as inovações podem ser classificadas ao longo de duas dimensões: impacto das inovações nos componentes; e impacto nas ligações entre os componentes. Dessa forma, inovação radical e incremental são pontos extremos ao longo dessas dimensões. A Figura 3 apresenta mais dois tipos de inovação de acordo com Henderson e Clark (1990): inovação modular e inovação arquitetural. Inovação modular modifica o conceito do design dominante de uma tecnologia e inovação arquitetural gera novas interações e novas ligações entre os componentes de um produto estabelecido.

A classificação proposta por Henderson e Clark (1990) está focada no impacto da inovação sobre a utilidade de uma arquitetura existente e sobre o conhecimento da empresa sobre o componente. Por este motivo, os autores consideram importante a idéia de design dominante e construção de conhecimento e competência das organizações a partir de tarefas recorrentes, por serem os principais conceitos para compreender o conhecimento arquitetural.

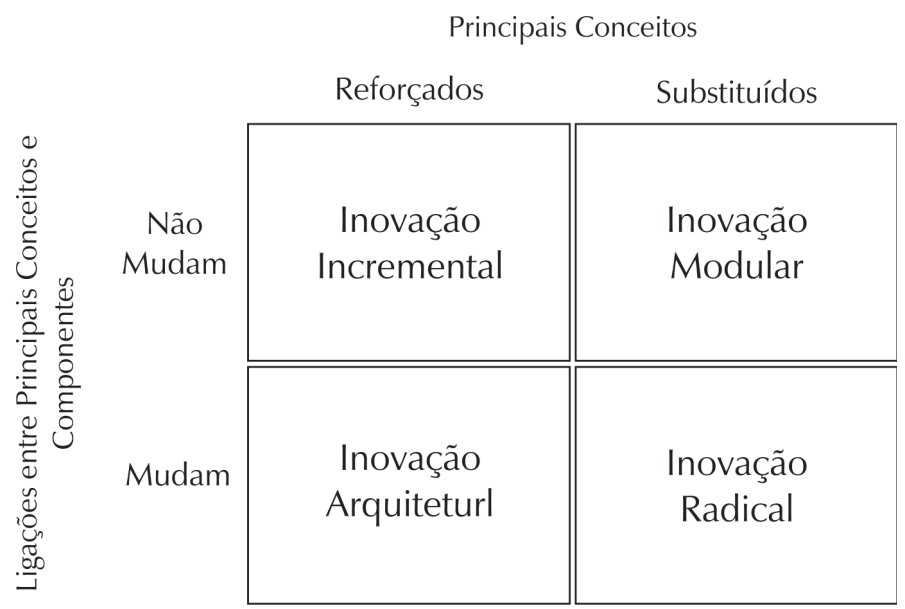

Fonte: Henderson e Clark (1990, p.12).

Figura 3 - Framework de Henderson e Clark. 
Autores mais normativos, como Wheelwright e Clark (1992, p.35), consideram que o desenvolvimento de inovação em produtos e processos em uma organização deve ter:

- foco no consumidor: equilíbrio para alcançar integração entre áreas e obter resultados para problemas específicos de áreas funcionais;

- disciplina: processo de desenvolvimento é complexo, utilização de fases de desenvolvimento, critérios claros para mudança de fase, procedimentos de teste, desenvolvimento de protótipos;

- coerência nos detalhes: processo de desenvolvimento deve manter coerência entre seus diferentes elementos;

- alinhamento com a missão: empresa deve saber qual o seu core business e como o ambiente pode afetar seu negócio, empresas que enfrentam diferentes ambientes precisam de mais de um sistema de desenvolvimento;

- padronização: criação de um padrão de desenvolvimento, um modelo de como idéias são transformadas em produtos e processos comerciais, facilita comunicação e o processo de desenvolvimento.

Assim, a partir desses estudos na indústria manufatureira, Gallouj e Weinstein (1997) fazem uma análise teórica que aumenta o espectro dos modelos para torná-los mais adequados ao setor de serviços, não só respeitando várias das características desse setor, mas ainda extrapolando essas características.

Tether e Hipp (2002) verificaram fontes de competitividade e padrões de atividades relatadas de inovação entre empresas de serviços de conhecimento intensivo. A escolha dessas empresas deveu-se à sua significância: são dinâmicas e intelectualmente instigantes; estão em rápido crescimento; são bons exemplos das supostas particularidades dos serviços, trazendo à tona a importância da intangibilidade, da informação e do conhecimento processado e a estreita interação entre usuário-fornecedor do serviço; e são importantes fontes de criação de conhecimento, podendo atuar em rede.

Dentre as conclusões às quais os autores chegaram encontram-se (TETHER e HIPP, 2002):

- empresas de serviços tendem a focar-se em qualidade e flexibilidade mais que em preço, para atender às diferentes necessidades de seus clientes;

- a boa vontade para adaptar serviços para necessidades específicas dos usuários apareceu em grande parte das empresas com ganhos de receita com serviços customizados e "sob medida";

- os padrões de investimento mostraram diferenças interessantes. Empresas de alta intensidade e técnicas investem menos (por empregado) em máquinas e equipamentos. Porém investem mais em tecnologia de informação;

- a maior parte das empresas disse ter inovado e houve pequena diferença na proporção de inovação entre os quatro tipos analisados;

- outras empresas foram freqüentemente reconhecidas como importantes fontes de informação e foram pouco convidadas para uma colaboração formal para inovação.

\section{Considerações finais}

Gallouj (1997) procura estabelecer a relação entre paradigma tecnológico e inovação no setor de serviços. O autor explica que os serviços devem ser analisados em sua relação com os demais setores da atividade econômica, em especial com a indústria, sob a ótica dos impactos que the são causados. Conforme o autor, o modelo do "ciclo reverso do produto" reforça a concepção de que a indústria é o local da inovação e caracteriza-o como um modelo 
de análise dos impactos da tecnologia da informação sobre os serviços. Assim, o autor conclui que o modelo não pode ser aplicado à maioria dos outros casos para estudo da inovação em serviços. Gallouj (1998) ressalta também a importância das inovações institucionais ou organizacionais. Essas inovações institucionais dariam origem a trajetórias institucionais ou organizacionais, sendo a combinação e evolução dessas trajetórias únicas, de acordo com as opções que as empresas estabelecem.

Kon (2004) comenta que, no contexto da heterogeneidade das atividades de serviços, boa parte das empresas é tão inovativa quanto nas atividades manufatureira. A autora explica que, hoje em dia, há necessidade de se questionar a tradicional idéia de baixa produtividade e inércia produtiva como características dos serviços. As atividades de serviços de informação têm levado ao setor de serviços o crescimento da produtividade do trabalho e do capital.

Essa idéia complementa a colocação de Agnihothri et al. (2002), ao explicarem que alguns autores atribuem o problema de produtividade na indústria de serviços ao mau uso da tecnologia de informação, enquanto outros argumentam que a mensuração tradicional de produtividade não captura o verdadeiro valor da tecnologia. Comentam que pouco é sabido ainda sobre os impactos da tecnologia na qualidade do serviço, no valor percebido e na lealdade dos clientes. Esses autores explicam, ainda, que o papel das pessoas, da tecnologia e dos sistemas organizacionais precisa ser considerado e retratado em uma inovação de serviço dirigida pela tecnologia.

Dessa forma, Agnihothri et al. (2002) propõem um modelo para análise, formulação e implementação de estratégias em serviços que considera o impacto da tecnologia em três dimensões: empregados, clientes e organização. Esse modelo considera as ligações entre esses três elementos e a relação deles com a tecnologia. Os autores crêem que se a organização considerar esses três elementos e suas ligações, a tecnologia pode aumentar a efetividade dos serviços, aumentando a produtividade da empresa e a satisfação dos clientes.

Kandampully (2002) explica que o aumento do uso da tecnologia na maior parte das áreas adicionou conhecimento em todos os tipos de trabalho e requereu que as empresas buscassem empregados dispostos a investir em conhecimentos vindouros. Dentro desse novo paradigma, o autor explica que experiência tem valor limitado, uma vez que novo conhecimento é essencial para tornar a organização produtiva com a adoção de novas tecnologias. Apesar de esta ser uma afirmação questionável, pois o autor não está considerando que experiência traz conhecimento acumulado que pode ser utilizado sob diferenciadas formas, combinações e para diferentes soluções, a conclusão à qual ele chega é inegável: conhecimento e melhoria dos componentes de serviço têm implicações significativas para mercado de trabalho e para a indústria.

Miozzo e Soete (2001) foram corroborados com a colocação dos autores anteriores, pois já haviam explicitado que faz parte do passado a idéia de que as atividades de serviços são intensivas em trabalho e com pequeno escopo no aumento de produtividade. Na verdade, os autores foram além, explicando que há necessidade de se entender a importância crescente da informação no setor de serviços e que as peculiaridades deste setor são produtoras de tecnologia. Para esses autores, as mudanças tecnológicas geraram três grandes mudanças na estrutura e gerenciamento dos serviços: o aumento das ligações entre produção de bens e serviços, o aumento da transportabilidade dos serviços e o aumento do conhecimento intensivo em serviços.

Com base nessas idéias centrais, Miozzo e Soete (2001) sugerem uma classificação de serviços cuja ênfase está na interação entre manufatura e serviços, ambos em termos da origem e aplicação de mudança tecnológica. Apesar de os autores criticarem a taxonomia de 
Pavitt (1984), em virtude de este autor classificar todos os serviços em um único setor dentre os quatro padrões setoriais de inovação que ele identificou em seus estudos, pode-se perceber, no Quadro 1, a seguir, que o estudo de Miozzo e Soete (2001) está diretamente embasado pela taxonomia proposta por Pavitt (1984).

\begin{tabular}{|l|l|}
\hline \multicolumn{1}{|c|}{ Taxonomia de Pavitt } & Classificação de Miozzo e Soete \\
\hline $\begin{array}{l}\text { Setor dominado pelo fornecedor: as prin- } \\
\text { cipais inovações foram geradas fora do } \\
\text { setor, em geral, pelos fornecedores. }\end{array}$ & $\begin{array}{l}\text { Dominado pelo fornecedor: principal- } \\
\text { mente serviços pessoais e serviços públi- } \\
\text { cos e sociais. }\end{array}$ \\
\hline $\begin{array}{l}\text { Setor intensivo em escala: inovação em } \\
\text { produtos e processos na busca de redução } \\
\text { de custos e diferenciação do produto }\end{array}$ & $\begin{array}{l}\text { Redes físicas intensivas em escala e Redes } \\
\text { de informação: inovação fortemente } \\
\text { determinada pelo uso do serviço. }\end{array}$ \\
\hline $\begin{array}{l}\text { Setor fornecedor especializado: deter a } \\
\text { tecnologia é o principal fator de concor- } \\
\text { rência. }\end{array}$ & $\begin{array}{l}\text { Baseado em ciência e Fornecedor espe- } \\
\text { cializado: serviços de pesquisa, desenvol- } \\
\text { vimento e atividades de software de firmas } \\
\text { no setor. }\end{array}$ \\
\hline $\begin{array}{l}\text { Setor baseado em ciência: desenvolvem } \\
\text { conhecimento na fronteira com as ciên- } \\
\text { cias básicas. }\end{array}$ & \\
\hline
\end{tabular}

Fonte: Adaptado de Pavitt (1984) e de Miozzo e Soete (2001).

Quadro 1 - Comparação entre a taxonomia de Pavitt e a classificação de Miozzo e Soete

Miozzo e Soete (2001) complementam, explicando que os serviços intensivos em tecnologia usam e desenvolvem ativamente dados, comunicação, guarda e transmissão de informação. $E$, finalmente, colocam que os dois grandes fatores que permitiram o grande crescimento da utilização da tecnologia de informação nos serviços foram a digitalização e a microeletrônica.

Finalmente, muito já se estudou sobre inovação em indústrias manufatureiras. Utterback (1994) estudou diferentes indústrias, incluindo indústrias de bens não-montados (como o vidro) no intuito de compreender como se dá o processo de inovação e como acontece a dominância de design. Henderson e Clark (1991) buscaram compreender os tipos de inovações possíveis a partir dos componentes do produto e das ligações entre esses componentes. Pavitt (1984) propôs uma taxonomia para inovação nas indústrias considerando a sinergia entre as organizações.

Também no setor de serviços são encontrados estudos sobre inovação, propondo classificações genéricas, principalmente a partir das mudanças tecnológicas e/ou integradoras, haja vista os estudos de Barras (1986), Shostack (1987), Gallouj e Weinstein (1997), Miozzo e Soete (2001), entre outros. Mas esses estudos não consideram uma análise longitudinal das empresas prestadoras de serviços, nem buscaram compreender como acontece o processo de adoção dessas inovações ao longo do tempo dentro dessas organizações. 


\section{Referências bibliográficas}

ABERNATHY, W.; CLARK, K. Innovation: mapping the winds of creative destruction. Research Policy, v.14, p.3-22, 1985.

ABRAMOVICI, M.; BANCEL-CHARENSOL, L. How to take custumers into consideration in service innovation projects. The Service Industries Journal, v.24, n.1, p.56-78, Jan. 2004.

BARRAS, R. Towards a theory of innovation in services. Research Policy, v.15, p.161-173. 1986.

COLLIER, D.; MEYER, S. A service positioning matrix. International Journal of Operations and Production Management, v.18, n.12, p.12231244, 1998.

DOSI, G. Technological paradigms and technological trajectories. A suggested interpretation of the determinants and directions of technical change. Research Policy, v.11, p.147-162, 1982. FITZSIMMONS, J.; FITZSIMMONS, M. Administração de serviços. 2. ed. Porto Alegre: Bookman, 2000.

GALLOUJ, F. Innovating in reverse: services and the reverse product cycle. European Journal of Innovation Management, Bradford, v.1, Iss.3, p.123, 1998.

GALLOUJ, F. Innovation theory: towards a neoShumpeterian theory of innovation in services? Science and Public Policy, v. 24, n. 6, p.405420, dec. 1997.

GALLOUJ, F.; WEINSTEIN, O. Innovation in services. Research Policy, v. 26, p.537-556, 1997.

GOPALAKRISHNAN, S.; DAMANPOUR, F. A review of innovation research in economics, sociology and technology management. Omega, v.25, n.1, p.15-28, 1997.

HENDERSON, R.; CLARK, K. Architectural innovation: the reconfiguration of existing product technologies and the failure of established firms. Administrative Science Quarterly, v.35, n.1. p.9-30, Mar. 1990.
HESKETT, J.; SCHLESINGER, L. A cadeia serviçoslucro: justificando a excelência. In: __. Lucro na prestação de serviços. New York: The Free Press, 1997.

IBGE. Instituto Brasileiro de Geografia e Estatística. Disponível em: <http://www.ibge.gov. br. >. Acesso em: 20 mar. 2005.

KANG, H.; McDERMOTT, C. A Classification scheme of services and its implications for technology management in services. Technology management - Strategies \& Applications, v.5, p.203-213, 2000.

KINGMAN-BRUNDAGE, Jane. Service mapping: back to basics. In: GLYNN, W.; BARNES, J. Understanding services management. Chichester: John Wiley \& Sons, 1995.

MIOZZO, M.; SOETE, L. Internationalization of services: a technological perspective.

Technological Forecasting and Social Change, v. 67, p.159-185, 2001.

PAVITT, K. Sectoral patterns of technical change: towards a taxonomy and a theory. Research Policy, v.13, p.343-373, 1984.

SILVESTRO, R. Positioning services along the volume-variety diagonal: the contingencies of service design, control and improvement. International Journal of Operations and Production Management, v. 9, n. 4, p. 399-420, 1999.

SHOSTACK, G. How to design a service.

European Journal of Marketing, v.16, p.49-63, 1982.

Service positioning through strutuctural change. Journal of Marketing, v.51, p.34-43, Jan. 1987.

SUNDBO, J; GALLOUJ, F. Innovation in service. PREST - Policy Research in Engineering, Science \& Technology, Manchester, 1998. (Project Report S2).

TETHER, Bruce; HIPP, Christiane. Knowledge intensive, technical and other services: patterns of competitiveness and innovation compared. 
Technology Analisys \& Strategic Management, v.14, n.2, p.163-182, 2002.

UTTERBACK, James. Mastering the dynamics of innovation: how companies can seize opportunities in the face of technological change. Boston, Massachusetts: Harvard Business School Press, 1994.

ZARIFIAN, P. Mutação dos sistemas produtivos e competências profissionais: a produção industrial de serviço. In: SALERNO, M. Relação de serviço: produção e avaliação. São Paulo: SENAC, 2001a. Cap. 2. p.67-93.
ZARIFIAN, P. Valor, organização e competência na produção de serviço: esboço de um modelo de produção de serviço. In: SALERNO, M.

Relação de serviço: produção e avaliação. São Paulo: SENAC, 2001b. Cap. 3. p.95-149. 